\title{
NEW ROUTE FOR THE SYNTHESES OF SOME NOVEL DERIVATIVES OF 3-ARYL BENZO[d] THIAZOLE-2(3H)-IMINE FROM HIGH SUBSTITUTED THIOUREAS
}

\author{
MARZIEH MIAR ${ }^{a}$, KHALIL POURSHAMSIAN $^{a *}$, ABOLFAZL SHIROUDI ${ }^{b^{*}}$, FARHAD HATAMJAFARI $^{a}$ AND \\ AHMAD REZA OLIAEY ${ }^{a}$
}

${ }^{a}$ Chemistry Department, Tonekabon Branch, Islamic Azad University, Tonekabon, Iran.

${ }^{b}$ Young Researchers and Elite Club, East Tehran Branch, Islamic Azad University, Tehran, Iran.

\begin{abstract}
We have developed herein a new approach to the diverse synthesis of novel derivatives of 3-aryl benzo[d]thiazole-2(3H)-imines (3a-g), by a two-component reaction between diazonium salt (2) and various synthesized $N$-acyl- $N^{\prime}$-aryl thioureas (1a-g), in the presence of sodium tert-butoxide as strong base. Finally, it resulted in the production of the desired products with a moderate yield. The chemical structures of these synthesized compounds were confirmed by various physico-chemical methods viz. FT-IR, ${ }^{1} \mathrm{H}-\mathrm{NMR},{ }^{13} \mathrm{C}-\mathrm{NMR}$, and elemental analysis.
\end{abstract}

Keywords: 3-aryl benzo[ $[d]$ thiazole-2(3H)-imines, Diazonium salt, $N$ - acyl- $N$ '-aryl thiourea.

\section{INTRODUCTION}

Fused heterocyclic compounds are the key valuable and structural scaffolds in a broad variety of natural products, drug molecules, and functional materials [13]. Among them, the analogues of benzothiazole and its derivatives have a significant role due to their wide variety of biological activities and applications in the pharmaceutical industry. Benzothiazole is an organosulfur, as well as organonitrogen heterocyclic compound was a which benzene ring is fused with thiazole [4-13]. Benzothiazoles are an important class of heterocyclic compounds that act as core nucleus in various drugs such as anticancer [5,14], antileishmanial [15], antimicrobial [9,16], anti-asthmatic [11], antitumor [6], antibacterial [17,18], anti-tubercular,[19] anticonvulsant [4,20], anti-HIV $[15,21]$, anti-inflammatory [5,7], antifungal $[9,13]$, antiproliferative [6,14,21,22], antiviral [23], anti-Alzheimer [10,14], antimalarial [15], and antidiabetic [24-26] effects. The related research and developments in BTA-based medicinal chemistry have become a rapidly developing and increasingly active topic $[6,19]$.

Various methods have been reported for the synthesis of benzothiazole derivatives. A survey of the literature showed that there are limited means to generate them. Nevertheless, some methods suffer from disadvantages such as high temperature, long reaction time, tedious work-up procedures, use of toxic metallic compounds, toxic and volatile solvents, and chromatographic separation. As a consequence, designing environmentally benign methods is a challenge for researchers. In recent decades, great efforts have been devoted to exploring novel, convenient, and efficient synthetic routes [27-29].

Thiourea and its derivatives with the general formula $\left(R^{1} R^{2} N\right)\left(R^{3} R^{4} N\right) C S$, are a valuable functional group in organic chemistry. Thioureas are used as the building blocks in the preparation of the heterocyclic compounds. Therefore, the syntheses of its derivatives have been the subject of gained interest as a precursor of the wide variety of biologically active compounds for many years [30-32]. Herein, we have prepared $N$-acyl- $N$ '-aryl thiourea derivatives by the reaction of acyl halides, ammonium thiocyanate, and aryl amines with satisfactory yields. The reaction was performed under reflux conditions.

Diazonium compounds have been investigated extensively since the first one reported in 1858. They can be used as valuable building blocks or intermediates in a wide range of organic syntheses. Generally, the synthesis of an aromatic diazonium salt is initiated by the diazotization of an aromatic amine with sodium nitrite and a mineral acid. Nevertheless, the diazonium salts are most generally used in situ without isolation due to their extremely dangerous nature rising from low thermal stability and chemical instability [33-35].

In this study for the first time, we reported a new route for the synthesis of some 3-aryl benzo[ $d]$ thiazole-2(3H)-imine derivatives. At the first stage of the survey, we optimized the synthesis method of the compound from accessible reagents. Finally, target products were developed through reaction different types of synthesized $N$-acyl- $N$ '-aryl thiourea derivatives with a diazonium salt in the presence of an excess of sodium tert-butoxide as a bulky strong non-nucleophilic base with moderate yield [36-38]. The results of this study and the details of the employed methodology are mentioned in the next sections.

\section{EXPERIMENTAL}

\section{Chemicals and reagents}

All chemicals used in this study are of high analytical grade. They were obtained from (either Sigma-Aldrich or Merck). In all cases, the product's structure was identified by their FT-IR, ${ }^{1} \mathrm{H}$ - and ${ }^{13} \mathrm{C}-\mathrm{NMR}$. The purification of products was performed via recrystallization by $n$-hexane. All the melting points were measured with an electro thermal type 9100 melting points apparatus and have not been corrected. Thin-layer chromatography (TLC) was performed using HF254 fluorescent silica gel plates (Merck), and spots were detected under UV light at $254 \mathrm{~nm}$. Infrared spectra (IR: $v / \mathrm{cm}^{-1}$ ) were obtained on Shimadzu IR470 , using $\mathrm{KBr}$ disks. ${ }^{1} \mathrm{H}-\mathrm{NMR}$ and ${ }^{13} \mathrm{C}-\mathrm{NMR}$ spectra were recorded at $293 \mathrm{~K}$ on a Bruker Avance DRX-250 (250 MHz) spectrometer. NMR spectra were acquired in base-filtered deuterated chloroform $\left(\mathrm{CDCl}_{3}\right)$ solvents containing Tetramethylsilane (TMS) as an internal standard at $250.1 \mathrm{MHz}$ and $62.8 \mathrm{MHz}$. Elemental analyses were carried out on a Carlo-Erba EA1110 CNNO-S analyzer and agreed with calculated values.

General procedure for the preparation of 3-aryl benzo[d]thiazole-2(3H)imine derivatives $(3 \mathbf{a}-\mathrm{g})$

Thiourea derivatives (1a-g) and the diazonium salt (2) were prepared by the previously reported chemical techniques [39-41]. To a vigorously stirred cold $\left(0-5{ }^{\circ} \mathrm{C}\right)$ solution of yellow diazonium crystals (2), a solution of thiourea (1a) $0.256 \mathrm{~g}(1 \mathrm{mmol})$ in acetone $(15 \mathrm{ml})$ added slowly in sodium tert-butoxide media for $20 \mathrm{~min}$, The reaction mixture was allowed to stir vigorously under controlled temperature at $0-5{ }^{\circ} \mathrm{C}$ for $2-3 \mathrm{hrs}$. In the following, the reaction mixture was stirred under reflux conditions for further $45 \mathrm{~min}$ to complete the reaction. The progress of the reaction was monitored by TLC using $n$-hexane: ethyl acetate $(3: 1)$ as eluent to confirm the accuracy.

Upon completion of the reaction, washing and purification operations were carried out, then the synthesized compound was separated by simple filtration and purified by recrystallization from $n$-hexane, at high purity. After drying, pure light brown solid (3a) with melting point $114-116^{\circ} \mathrm{C}$ and yield $74 \%$ obtained. The chemical structures of the product has been confirmed by various physico-chemical methods viz. FT-IR, ${ }^{1} \mathrm{H}-\mathrm{NMR},{ }^{13} \mathrm{C}-\mathrm{NMR}$ and elemental analysis, accordingly the other desired derivatives were prepared by the same method. The synthetic route to compounds (3a-g) is outlined in Scheme 1. 
The structure and physical data of products are presented in Table 1.

Table 1. The structure and physical data of products

\begin{tabular}{|c|c|c|c|c|}
\hline Entry & Thiourea no. & Product $^{a}$ & m.p. $\left({ }^{\circ} \mathbf{C}\right)$ & Yield (\%) ${ }^{b}$ \\
\hline 1 & $1 \mathrm{a}$ & & $114-116$ & 74 \\
\hline 2 & $1 \mathrm{~b}$ & & $109-111$ & 73 \\
\hline 3 & $1 c$ & & $115-117$ & 68 \\
\hline 4 & 1d & & $105-107$ & 72 \\
\hline 5 & 1e & & $106-109$ & 79 \\
\hline 6 & 1f & & $115-117$ & 75 \\
\hline 7 & $1 \mathrm{~g}$ & & $\begin{array}{c}\text { Unknown } \\
\text { (decomp. } \geq 180)\end{array}$ & 70 \\
\hline
\end{tabular}

${ }^{a}$ Compounds were prepared in the presence of sodium tert-butoxide ${ }^{b}$ Isolated yields

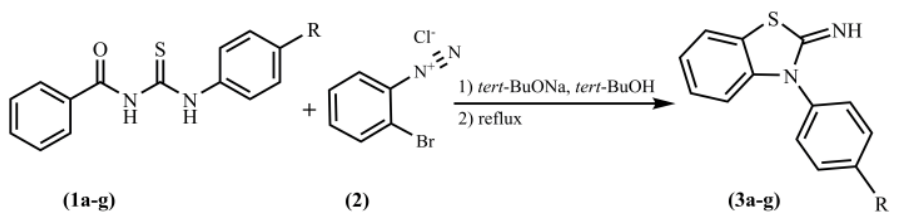

$\mathrm{R}=\mathrm{H}(\boldsymbol{a}), \mathrm{Cl}(\boldsymbol{b}), \mathrm{NO}_{2}(\boldsymbol{c}), \mathrm{Ph}(\boldsymbol{d}), \mathrm{CH}_{3}(\boldsymbol{e}), \mathrm{Br}(f), \mathrm{F}(\boldsymbol{g})$

Scheme 1. The synthetic route of compounds $3 \mathrm{a}-\mathrm{g}$
Physical and spectroscopic data for products (3a-g)

3-phenyl benzo[ $d]$ thiazole-2(3H)-imine (3a)

Light brown solid; yield: $74 \%$, m.p.: $114-116^{\circ} \mathrm{C}$, FT-IR (KBr): $3306(\mathrm{NH})$, $1595\left(\mathrm{C}=\mathrm{N}_{\text {imine }}\right) \mathrm{cm}^{-1} .{ }^{1} \mathrm{H}-\mathrm{NMR}: 7.03-7.67(9 \mathrm{H}, \mathrm{m}, \mathrm{Ar}-\mathrm{H}), 10.1(1 \mathrm{H}, \mathrm{s}, \mathrm{N}-\mathrm{H})$. ${ }^{13} \mathrm{C}-\mathrm{NMR}\left(\delta \mathrm{ppm}, \mathrm{CDCl}_{3}, 62.89 \mathrm{MHz}\right): 117.8,122.1,126.7,127.6,128.3,129.3$, 129.9, 131.1, 131.7, 133.2, and 135.8. Anal. For $\mathrm{C}_{13} \mathrm{H}_{10} \mathrm{~N}_{2} \mathrm{~S}$ (226) Calcd.: C 69.03; H 4.42; N 12.39; S $14.16 \%$, Found: C 68.97; H 4.45; N 12.43; S $14.15 \%$.

\section{3-(4-chlorophenyl) benzo[ $d]$ thiazole-2(3H)-imine (3b)}

Dark orange solid; yield: $73 \%$, m.p.: $109-111^{\circ} \mathrm{C}$, FT-IR (KBr): $3305(\mathrm{NH})$, $1595\left(\mathrm{C}=\mathrm{N}_{\text {imine }}\right) \mathrm{cm}^{-1} .{ }^{1} \mathrm{H}-\mathrm{NMR}: 7.1(\mathrm{~d}, \mathrm{~J}=6.5 \mathrm{~Hz}, 2 \mathrm{H}, \mathrm{Ar}-\mathrm{H}), 7.24-7.67(\mathrm{~m}$, $6 \mathrm{H}, \mathrm{Ar}-\mathrm{H}), 10.1(1 \mathrm{H}, \mathrm{s}, \mathrm{N}-\mathrm{H}) .{ }^{13} \mathrm{C}-\mathrm{NMR}\left(\delta \mathrm{ppm}, \mathrm{CDCl}_{3}, 62.89 \mathrm{MHz}\right): 114.8$, $116.1,117.8,126.4,128.01,128.3,129.4,133.2,145.9,146.2,149.3$. Anal. For $\mathrm{C}_{13} \mathrm{H}_{9} \mathrm{~N}_{2} \mathrm{SCl}(260.45)$ Calcd.: C 59.90; H 3.45; N 10.75; S $12.29 \%$, Found: C 59.86; H 3.47; N 10.79; S $12.34 \%$.

\section{3-(4-nitrophenyl) benzo[d]thiazole-2(3H)-imine (3c)}

Brownish yellow solid; yield: $68 \%$, m.p.: $115-117^{\circ} \mathrm{C}$, FT-IR (KBr): 3306 $(\mathrm{NH}), 1595\left(\mathrm{C}=\mathrm{N}_{\text {imine }}\right), 1262,1467\left(\mathrm{NO}_{2}\right) \mathrm{cm}^{-1} .{ }^{1} \mathrm{H}-\mathrm{NMR}: 7.19-7.43(8 \mathrm{H}, \mathrm{m}$, $\mathrm{Ar}-\mathrm{H}), 9.8(1 \mathrm{H}, \mathrm{s}, \mathrm{N}-\mathrm{H}) .{ }^{13} \mathrm{C}-\mathrm{NMR}\left(\delta \mathrm{ppm}, \mathrm{CDCl}_{3}, 62.89 \mathrm{MHz}\right): 117.8,122.1$, 126.7, 127.6, 128.3, 129.3, 129.9, 131.1, 131.7, 133.2, and 135.8. Anal. For $\mathrm{C}_{13} \mathrm{H}_{9} \mathrm{~N}_{3} \mathrm{O}_{2} \mathrm{~S}(271)$ Calcd.: C 57.56; H 3.32; N 15.50; S $11.81 \%$, Found: C 57.54; H 3.35; N 15.54; S $11.77 \%$.

\section{3-(naphthyl) benzo[d]thiazole-2(3H)-imine (3d)}

Brownish yellow solid; yield: $72 \%$, m.p.: $105-107{ }^{\circ} \mathrm{C}$, FT-IR (KBr): 3305 $(\mathrm{NH}), 1595\left(\mathrm{C}=\mathrm{N}_{\text {imine }}\right) \mathrm{cm}^{-1} .{ }^{1} \mathrm{H}-\mathrm{NMR}: 7.05-8.05(11 \mathrm{H}, \mathrm{m}, \mathrm{Ar}-\mathrm{H}), 10.1(1 \mathrm{H}, \mathrm{s}$, $\mathrm{N}-\mathrm{H}) .{ }^{13} \mathrm{C}-\mathrm{NMR}\left(\delta \mathrm{ppm}, \mathrm{CDCl}_{3}, 62.89 \mathrm{MHz}\right): 117.7,121.7,123.8,125.3,126.4$, 126.9, 127.6, 127.9, 128.3, 128.6, 129.2, 131.5, 133.2, 133.8, 134.1, 167.2, 180.04. Anal. For $\mathrm{C}_{17} \mathrm{H}_{12} \mathrm{~N}_{2} \mathrm{~S}$ (276) Calcd.: C 73.91; H 4.35; N 10.14; S $11.59 \%$, Found: C 73.88; H 4.32; N 10.17; S $11.63 \%$.

\section{3-(p-tolyl) benzo $[d]$ thiazole-2(3H)-imine (3e)}

Light brown solid; yield: $79 \%$, m.p.: 106-109 ${ }^{\circ} \mathrm{C}$, FT-IR (KBr): $3304(\mathrm{NH})$, $1595\left(\mathrm{C}=\mathrm{N}_{\text {imine }}\right) \mathrm{cm}^{-1} .{ }^{1} \mathrm{H}-\mathrm{NMR}: 2.3(\mathrm{t}, \mathrm{J}=4 \mathrm{~Hz}, 3 \mathrm{H}$, and $\mathrm{C}-\mathrm{H}), 7.05-7.67(8 \mathrm{H}, \mathrm{m}$, $\mathrm{Ar}-\mathrm{H}), 10.1(1 \mathrm{H}, \mathrm{s}, \mathrm{NH}) .{ }^{13} \mathrm{C}-\mathrm{NMR}\left(\delta \mathrm{ppm}, \mathrm{CDCl}_{3}, 62.89 \mathrm{MHz}\right): 29.7,114.7$, 115.7, 117.8, 119.4, 120.8, 124.7, 126.5, 128.3, 129.5, 130.3 and 133.2. Anal. For $\mathrm{C}_{14} \mathrm{H}_{12} \mathrm{~N}_{2} \mathrm{~S}$ (240) Calcd.: C 70; H 5; N 11.67; S $13.33 \%$, Found: C 69.98; H 4.96; N 11.71; S $13.35 \%$.

\section{3-(2-bromophenyl) benzo[d]thiazole-2(3H)-imine (3f)}

Yellow solid; yield: $75 \%$, m.p.: $115-117{ }^{\circ} \mathrm{C}$, FT-IR (KBr): $3306(\mathrm{NH}), 1595$ $\left(\mathrm{C}=\mathrm{N}_{\text {imine }}\right) \mathrm{cm}^{-1} .{ }^{1} \mathrm{H}-\mathrm{NMR}: 7.03-7.67(8 \mathrm{H}, \mathrm{m}, \mathrm{Ar}-\mathrm{H}), 10.1(1 \mathrm{H}, \mathrm{s}, \mathrm{NH}) \cdot{ }^{13} \mathrm{C}-$ $\operatorname{NMR}\left(\delta \mathrm{ppm}, \mathrm{CDCl}_{3}, 62.89 \mathrm{MHz}\right): 114.7,117.8,119.5,122.3,126.5,127.7$, 128.3, 130.1, 131.1, 133.2, 142.6. Anal. For $\mathrm{C}_{13} \mathrm{H}_{9} \mathrm{~N}_{2} \mathrm{SBr}$ (305) Calcd.: C 51.15; H 2.95; N 9.18; S $10.49 \%$, Found: C 51.18; H 2.97; N 9.21; S $10.43 \%$.

\section{3-(4-fluorophenyl) benzo $[d]$ thiazol-2(3H)-imine (3g)}

Dark yellow solid; yield: $70 \%$, m.p.: decomp. $\geq 180$, FT-IR (KBr): $3306(\mathrm{NH})$, $1595\left(\mathrm{C}=\mathrm{N}_{\text {imine }}\right) \mathrm{cm}^{-1} .{ }^{1} \mathrm{H}-\mathrm{NMR}: 7.03-7.67(8 \mathrm{H}, \mathrm{m}, \mathrm{Ar}-\mathrm{H}), 10.1(1 \mathrm{H}, \mathrm{s}$, $\mathrm{N}-\mathrm{H}) .{ }^{13} \mathrm{C}-\mathrm{NMR}\left(\delta \mathrm{ppm}, \mathrm{CDCl}_{3}, 62.89 \mathrm{MHz}\right): 114.8,116.1,117.8,126.4,128.01$, 128.3, 129.4, 133.2, 145.9, 146.2, and 149.3. Anal. For $\mathrm{C}_{13} \mathrm{H}_{9} \mathrm{~N}_{2} \mathrm{SF}$ (244) Calcd.: C 63.94; H 3.69; N 11.47; S 13.11 \%, Found: C 63.91; H 3.67; N 11.51; S 13.07 $\%$.

\section{RESULTS AND DISCUSSION}

In the present study, we have reported a new successful methodology to be a convenient route for the synthesis of efficient 3-aryl benzo[ $d]$ thiazole-2 $(3 H)$ imine derivatives. For this purpose, thiourea derivatives were selected as essential substances to achieve target products. In the following, after diazotization of primary aromatic amines, diazonium salts were faced with purified thioureas in situ. This approach has resulted in the removal of $\mathrm{N}_{2}$ from 
the reaction mixture. Subsequently, the cyclization reaction occurred by nitrogen attack leading to the removal of $\mathrm{Br}^{-}$. To conclude, all the desired final compounds were prepared under reflux conditions after the removal of the $\mathrm{PhCOBr}$ molecule. The TLC technique showed the formation of the desired products. Notably, the entire duration of the reaction, the mixture stirred vigorously and controlled temperature. A review of the authoritative literature shows that 3 -aryl benzo $[d]$ thiazole-2 $(3 H)$-imine $(\mathbf{3 a}-\mathbf{g})$ by this technique has not been reported previously.

The structures of all novel isolated products $(\mathbf{3 a}-\mathbf{g})$ were confirmed by spectroscopic (FT-IR, ${ }^{1} \mathrm{H}-\mathrm{NMR},{ }^{13} \mathrm{C}-\mathrm{NMR}$ ) data, and elemental analysis. The FT-IR spectra of the seven newly synthesized compounds showed a similar trend of stretching frequency modes. The FT-IR spectrum of the compound (3a) reveals the presence of stretching vibration for $\mathrm{N}-\mathrm{H}$ bands at $3306 \mathrm{~cm}^{-1}$. Furthermore, the sharp absorption peak in the region $v 1595 \mathrm{~cm}^{-1}$ indicates the presence of $\mathrm{C}=\mathrm{N}$ imine stretching bands. The ${ }^{1} \mathrm{H}-\mathrm{NMR}$ spectra of the compound (3a) in $\mathrm{CDCl}_{3}$ indicated multiple signals in the regions of $\delta 7.03-7.67 \mathrm{ppm}$ due to the aromatic protons. Amino protons appear at $\delta 10.1 \mathrm{ppm}$. For the ${ }^{13} \mathrm{C}$ spectrum of the assumed structure (3a), eleven signals appeared in the range of $\delta 117.8-135.8 \mathrm{ppm}$, in agreement with the proposed structure of compounds.

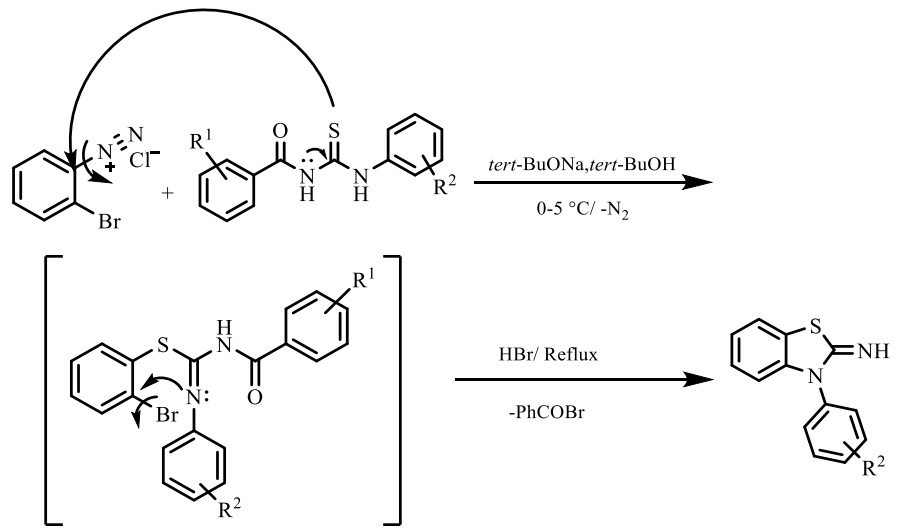

Scheme 2: The proposed mechanism for reaction.

In the proposed mechanism (see Scheme 2), the nucleophilicity power of the sulfur atom by the driving force of lone pair electrons of Nitrogen in tert-BuONa, tert-BuOH media at $0-5{ }^{\circ} \mathrm{C}$ was promoted. Afterward, the sulfur of thiourea with high ability nucleophilic effect was attacked to diazonium salt as a model substrate led to the removal of $\mathrm{N}_{2}$ and condensed to each other in order to afford suggested intermediate. In continue the whole stirred reaction mixture moved to reflux conditions. Consequently, the tendency of rich nitrogen to eliminate $\mathrm{Br}^{-}$ provides the intramolecular cyclization to the benzo[ $[d]$ thiazole-2 $(3 H)$-imine followed by acidic hydrolysis to remove the $\mathrm{PhCOBr}$ molecule.

It is clear that despite changing $\mathrm{R}^{1}$ in thioureas, the structure of all final compounds looks quite similar. Comparatively experimental results revealed that the selection of $\mathrm{R}^{1}=\mathrm{CH}_{3}, \mathrm{C}_{2} \mathrm{H}_{5}, \mathrm{CN}, \mathrm{NO}_{2}$ either in para or meta positions led to the same product $\left[\mathrm{R}^{1}=\mathrm{H}\right]$.

The well worth further investigation on substituents' influence on the aromatic ring upon the reaction yields has produced some further encouraging results in the field of benzotriazole analysis. It is also notable that electron-withdrawing groups $\mathrm{R}^{2}$ (entry=3,4,7 in Table 1 ) with the reduction of electron density on the nitrogen atom accordingly decreasing nucleophilicity effect, the reaction including long reaction times with low yields. In contrast, an electron-donating substitution (entry $=5$ in Table 1 ) had significant advantages. The results have shown that with the increase of the nitrogen's nucleophilicity, the reaction occurs faster and gives a higher yield.

\section{CONCLUSIONS}

In summary, we have developed a functional, effective, and operationally simple convergent protocol to provide the benzothiazole with readily synthesized use of thiourea as a precursor. The present methodology reported the syntheses of a novel series of 3-aryl benzo[d]thiazole-2(3H)-imines (3a-g), with simple workup and reasonable yield in the new route. Furthermore, the chemical composition of the benzothiazole derivatives was confirmed by spectroscopic results and elemental analysis.

\section{REFERENCES}

1. R. Sreedevi, S. Saranya, K. R. Rohit, G. Anilkumar, Adv. Synth. Catal. 361, 2236 (2019).

2. N. Kaur, P. Bhardwaj, M. Devi, Y. Verma, P. Grewal, Synth. Commun. 49 , 1345 (2019).

3. L. Da Costa, E. Scheers, A. Coluccia, A. Rosetti, M. Roche, J. Neyts, T. Terme, R. Cirilli, C. Mirabelli, R. Silvestri, P. Vanelle, Eur. J. Med. Chem. 140, 528 (2017).

4. S. L. Khokra, K. Arora, S. A. Khan, P. Kaushik, R. Saini, A. Husain, Iran J. Pharm. Res. 18, 1 (2019).

5. S. Tariq, P. Kamboj, M. Amir, Arch. Pharm. (Weinheim) 352, 1 (2019).

6. P. C. Diao, W. Y. Lin, X. E. Jian, Y. H. Li, W. W. You, P. L. Zhao, Eur. J. Med. Chem. 179, 196 (2019).

7. G. Romeo, O. Prezzavento, S. Intagliata, V. Pittalà, M. N. Modica, A. Marrazzo, R. Turnaturi, C. Parenti, S. Chiechio, E. Arena, A. Campisi, G. Sposito, L. Salerno, Eur. J. Med. Chem. 174, 226 (2019).

8. L. Firoozpour, A. Mokhtari, S. Moghimi, M. Safavi, A. Foroumadi, J. Sci. Islam. Repub. Iran 29, 335 (2018).

9. M. Haroun, C. Tratrat, K. Kositsi, E. Tsolaki, A. Petrou, B. Aldhubiab, M. Attimarad, S. Harsha, A. Geronikaki, K. N. Venugopala, H. S. Elsewedy, M. Sokovic, J. Glamoclija, A. Ciric, Curr. Top. Med. Chem. 18, 75 (2018).

10. M. Chhabra, S. Sinha, S. Banerjee, P. Paira, Bioorg. Med. Chem. Lett. 26, 213 (2016).

11. J. Wu, H. Luo, T. Wang, H. Sun, Q. Zhang, Y. Chai, Tetrahedron 75, 1052 (2019).

12. M. G. Rabbani, T. Islamoglu, H. M. El-Kaderi, J. Mater. Chem. A 5, 258 (2017).

13. A. Rouf, C. Tanyeli, Eur. J. Med. Chem. 97, 911 (2015).

14. A. K. El-Damasy, J. H. Lee, S. H. Seo, N. C. Cho, A. N. Pae, G. Keum, Eur. J. Med. Chem. 115, 201 (2016).

15. R. S. Keri, M. R. Patil, S. A. Patil, S. Budagumpi, Eur. J. Med. Chem. 89 207 (2015).

16. B. Kumari, K. Chauhan, J. Trivedi, V. Jaiswal, S. S. Kanwar, Y. R. Pokharel, ChemistrySelect 3, 11326 (2018).

17. V. R. Mishra, C. W. Ghanavatkar, S. N. Mali, S. L. Qureshi, H. K. Chaudhari, N. Sekar, Comput. Biol. Chem. 78, 330 (2019).

18. F. Naaz, R. Srivastava, A. Singh, N. Singh, R. Verma, V. K. Singh, Bioorg Med. Chem. 26, 3414 (2018).

19. J. Graham, C. E. Wong, J. Day, E. McFaddin, U. Ochsner, T. Hoang, C. L. Young, W. Ribble, M. A. DeGroote, T. Jarvis, X. Sun, Bioorg. Med. Chem. Lett. 28, 3177 (2018).

20. H. Eshghi, F. Eshkil, A. Shokooh Saljooghi, M. Bakavoli, Org. Chem. Res. 5, 87 (2019).

21. P. Vicini, A. Geronikaki, M. Incerti, B. Busonera, G. Poni, C. A. Cabras, P. La Colla, Bioorg. Med. Chem. 11, 4785 (2003).

22. M. A. Abdelgawad, R. B. Bakr, H. A. Omar, Bioorg. Chem. 74, 82 (2017).

23. H. Zeng, P. Luo, M. Luo, H. Ding, Q. Ding, Tetrahedron 75, 130472 (2019)

24. P. S. Yadav, D. Prakash, G. P. Senthilkumar, Int. J. Pharm. Sci. Drug. Res. 3, 1 (2011).

25. B. Chugh, A. Kumar Singh, S. Thakur, B. Pani, A. Kumar Pandey, H. Lgaz, I- M. Chung, E. E. Ebenso, J. Phys. Chem. C 123, 22897 (2019).

26. R. K. Gill, R. K. Rawal, J. Bariwal, Arch. Pharm. (Weinheim) 348, 155 (2015).

27. C. Liao, U. J. Kim, K. Kannan, Environ. Sci. Technol. 52, 5007 (2018).

28. F. Ghanbari Pirbasti, N. Mahmoodi, J. Chin. Chem. Soc. Taip. 64, 80 (2017).

29. S. Muhammad, S. Kumar, J. Koh, M. Saravanabhavan, K. Ayub, M. Chaudhary, Mol. Simul. 44, 1191 (2018).

30. L. Antypenko, Z. Sadykova, K. Shabelnyk, F. Meyer, S. Kovalenko, V. Meyer, L -A. Garbe, K. Steffens, Arch. Pharm. (Weinheim) 352, 1 (2019).

31. H. Tavakol, A. Mahmoudi, M. A. Ranjbari, J. Sulfur Chem. 40, 113 (2019).

32. K. Pourshamsian, Int. J. Mol. Clin. Microbiol. 2, 310 (2013).

33. F. Fioresi, A. Rouleau, K. Maximova, J. Vieillard, W. Boireau, C. Elie Caille, C. Soulignac, R. Zeggari, T. Clamens, O. Lesouhaitier, N. Mofaddel, F. Le Derf, Mater. Today: Proc. 6, 340 (2019).

34. V. D. Filimonov, E. A. Krasnokutskaya, A. Z. Kassanova, V. A. Fedorova, K. S. Stankevich, N. G. Naumov, A. A. Bondarev, V. A. Kataeva, Eur. J. Org. Chem. 2019, 665 (2019).

35. M. A. Metwally, S. Bondock, E. -S. I. El-Desouky, M. M. Abdou, Am. J. Chem. 2, 347 (2013). 
36. J. H. Docherty, J. Peng, A. P. Dominey, S. P. Thomas, Nat. Chem. 9, 595 (2017).

37. J. Jeon, S. Y. Lee, C. H. Cheon, Adv. Synth. Catal. 361, 2360 (2019).

38. K. Adelani Alabi, J. Mosebolatan Jabar, FUNAI J. Sci. Technol. 3, 85 (2017).

39. M. Marzi, K. Pourshamsian, F. Hatamjafari, A. Shiroudi, A. R. Oliaey, Russ. J. Bioorg. Chem. 45, 391 (2019).
40. Z. Kazeminejad, K. Pourshamsian, F. Hatamjafari, A. Shiroudi, A. R. Oliaey, Russ. J. Org. Chem. 55, 1609 (2019).

41. M. R. Yazdanbakhsh, A. Ghanadzadeh, E. Moradi, J. Mol. Liq. 136, 165 (2007). 